\title{
New Technologies in Higher Education: Lower Attendance and Worse Learning Outcomes?
}

\author{
Pedro Gomis-Porqueras, Jürgen Meinecke and \\ José A. Rodrigues-Neto ${ }^{1}$
}

\section{Abstract}

This paper explores the incentives offered to students and instructors by new technologies that grant access to online class materials. We examine the consequences for attendance and composition of live lectures and argue that new technologies reduce attendance, and very likely reduce it differentially.

\section{Introduction}

Teaching technologies in higher education are rapidly evolving; but new opportunities do not always improve welfare. Peltzman (1975) provides a prominent example. He analyses the effects of safety capabilities on car-accident mortality and finds that they had no effect on the highway death toll. Regulations had required car manufacturers to install seat belts for all occupants, an energyabsorbing steering column, penetration-resistant windshields, dual-braking systems, and padded instrument panels in all new cars. Peltzman concludes that effectively there has been an increase in the total number of accidents due to the induced change in drivers' behaviour.

Economics can also offer useful insights into the behaviour response of students and lecturers to new classroom technologies. It can lay bare the channels through which availability of classroom technology affects attendance and learning outcomes. It can also help us understand if more technology is necessarily better for students, and it can help us avoid misguided policies.

During pre-literate times, most education was achieved through observation and imitation. Traditions, beliefs, values, practices, and local knowledge were

\footnotetext{
1 Research School of Economics, College of Business and Economics, Australian National University; pedro.gomis@anu.edu.au. We would like to thank William Coleman and an anonymous referee for valuable comments, as well as Merrilyn Lárusson for English editing. Any errors are our responsibility.
} 
passed orally from person to person for generations. This educational system forced students to be in direct contact with instructors. Moreover, the reviewing of information was limited to rote memorizing. ${ }^{2}$

The role of educators and students changed drastically after $3500 \mathrm{BC}$, as new technologies allowed writing systems to be used in the classroom. With written systems, students were not required to be in direct contact with the instructor and teaching materials could be more easily reviewed after the live class.

Today an 'educational revolution' is taking place thanks to the development of digital technologies. Students have greater flexibility through access to online class materials. Current technology is able to extend existing instructional activities, whether in face-to-face, fully online, or blended learning environments. While not intended as a complete replacement for in-class instruction, digital technologies adopted in the classroom offer three important benefits: an alternative when students miss class, an opportunity for content review, and content for online course development. These new technologies can have important consequences for students' attendance, class composition, and academic outcomes.

Recently, Australian universities have invested in incorporating and improving web-based lecture technologies in the teaching environment. Such digital technologies allow lecturers to provide, inter alia, lecture slides, homework assignments, and practice tests on 'web-based learning management systems' such as Moodle or WebCT. The possibilities for online lecture content are evolving rapidly. For example, the majority of classrooms at the Australian National University (ANU) are now equipped with hardware and software that digitally audiotapes lectures and automatically publishes them online on course websites. This allows students to easily access the information conveyed in the lecture. In 2009, the ANU introduced mandatory digital audio recording for all lectures and all subjects. ${ }^{3}$

To economists, any such mandatory policy raises a number of questions. Most importantly, is it likely to bring the best outcomes? How do students change their behaviour in response to the introduction of new teaching technologies? The same questions can be asked with regard to lecturers. Furthermore, how

\footnotetext{
2 See Adeyemi and Adeyinka (2002) and Akinnaso (1998) for more on this issue.

3 In 2010 the university changed its audio recording policy and slightly relaxed the conditions for providing digital lecture content. Currently, the ANU Code of Practice for Teaching and Learning requires that teachers 'provide flexible access to lecture content by one or more of the following: digital recording of lectures for the duration of the semester, appropriate notes for the duration of the semester, appropriate lecture slides for the duration of the semester. Recording, notes or slides are to be made available on the learning management system site for a course.'
} 
do the objectives of university administrators affect student outcomes? Do all students benefit from new technology in the classroom? If not, what type of student benefits, and what type loses?

We will not provide answers to these questions here. Instead, our aim is to illustrate how policies that govern the availability of web-based lecture content - in many cases imposed in good faith and with good intentions - can lead to adverse outcomes. The naïve notion that 'more online content is always better' is misleading and can lead to bad policy. This is because not everyone benefits from the availability of web-based content - something that the recent policy debate has ignored. This paper deals explicitly with the different incentives that agents experience, and considers the impact on student attendance, lecture composition, and lecturer behaviour. We argue that new technologies reduce attendance, and very likely reduce it differentially for different types/groups of students.

Our paper complements the increasing economics literature on flexible learning. Benzing and Christ's (1997) survey of 207 undergraduate economics instructors revealed that more were using interactive methods, class discussions, multimedia, and student participation in the mid-1990s than in the late 1980s. The authors concluded that educators have shown that more varied and active teaching yields better learning outcomes. In contrast, Guest (2005) provides a theoretical framework and survey evidence to determine the effect of flexible learning on students' academic achievements. ${ }^{4}$ He concludes that teaching methods that give students greater choice over their learning do not improve the academic achievements of all students. In particular, academically motivated students and females benefit from greater flexibility but the rest of the student population does not.

Economic theory has offered useful insights into the behaviour of students and lecturers. Prominent examples are that of Becker (1975, 1979, and 1982), Correa and Gruver (1987), and Guest (2001). Becker's classic papers examine the optimal allocation of lecturer time to different teaching and research outputs and how these choices change because quality signals are not perfect. Correa and Gruver consider an environment where the student values academic achievement as well as time allocated to other activities. The instructor values the student's academic outcome as well as time devoted to other activities. The efforts of the representative student are linked to the instructor's efforts through academic achievement, which depends on the time allocated to the education process by both the student and the lecturer. As a result of the public-good nature of student achievement, insufficient time is invested into academic achievement. In

4 The term 'flexible' is generally applied to the current practice of university teaching and learning because it allows a range of options for the students to learn outside the classroom. 
the same spirit, Guest proposes a non-cooperative game between the instructor and students to study the choice of teaching methods. The instructor's optimal choice balances the greater time cost of more-active teaching methods against better learning outcomes. This choice critically depends on the instructor's or the university's utility function and the students alternative use of time.

\section{New Technologies and Lecture Attendance}

Coincident with the introduction of web-based lecture technologies, the way university students use their time has drastically changed. Babcock and Marks (2010) analyse data for US college students from 1961 to 2003 and find that students now work more, enjoy more leisure hours, and study less. In 1961, full-time students allocated 40 hours per week to studying; by 2003 they were investing only between 23 and 26 hours into academic pursuits. The authors remark that 'For more recent cohorts, going to college full-time appears to have been, at best, a part-time job.' In addition, more full-time enrolled students have some form of paid employment during the semester. Average work hours increased from about four per week in 1961 to between 9.5 and 11 per week in 2003.

At Australian universities, McInnis and Hartley 2002 find that students worked 14.7 hours in the most recent week they were employed. ${ }^{5}$ These employment and attendance patterns vary by discipline, emphasising the importance of student, course, and labour-market heterogeneity. For instance, McInnis and Hartley (2002) find that students in Arts/Humanities/Social Science and Education work an average of 15.3 hours per week, students in the Sciences work 14.4 hours on average per week, and students in Commerce/Business/Administration work 16.4 hours on average per week.

These results on students' lecture attendance and labour supply suggest that absenteeism might be consistent with utility-maximizing behaviour. The issue becomes one of time allocation, as the students choose between competing academic and non-academic activities. These observations have been made previously in the literature; prominent examples are Schmidt (1983), Dolton, Marcenaro, and Navarro (2003), and Guest (2005).

The education literature offers some evidence on the effect of web-based lecture materials on lecture attendance. Massingham and Herrington (2006) report that one of the main reasons posited by students for not attending lectures is the

5 The authors find that 38 per cent of respondents are working 16 hours or more and 18 per cent are working 21 hours or more per week. Respondents with 15 and fewer contact hours worked an average of 15.3 hours, but once course contact hours went over 15, paid work hours began to drop - to 14.7 hours for those with 16-20 course contact hours and to 13.2 hours for those with 21 contact hours or more per week. 
availability of materials online. When asked why they did not attend lectures, 68.3 per cent of students surveyed at an Australian Group of Eight university reported that they could learn as effectively using digital audio recordings, as they could by attending the corresponding lecture in person (Gosper et al. 2008). Lecturers have also observed this trend: 55.1 per cent of academic staff reported that lecture attendance had decreased as a result of introducing digital audio recording of lectures.

These results support the view that classroom technology affects attendance adversely. We caution, however, that none of these findings have identified causal effects of new technology on attendance. They merely expose a correlation between availability of online lecture materials and attendance. If attendance numbers decrease because of the availability of web-based lecture materials, we do not understand perfectly the channels through which such an effect operates.

Economic theory can offer an additional structure to frame our thinking about these correlations. ${ }^{6}$ From the perspective of a student, how does the availability of online lecture material affect lecture attendance ${ }^{7}$ On the one hand, material available online could be a complement in the learning process, over and above attending the live lecture. On the other hand, web-based materials could be substitutes for lecture attendance. To the extent that online materials are regarded as complements in the learning process, lecture attendance could increase. To the extent that they are substitutes, attendance could decrease with the introduction of new web-based technologies. Students will be affected differently depending on whether they regard online content as a complement or a substitute to live lectures.

Alternative policies on online lecture content offer different degrees of complementarity in producing knowledge for those attending live lectures and substitutability for non-attendants. For any given course, different webbased technologies will have distinct effects on attendance, depending on their relative degrees of complementarity and substitutability. Moreover, the degrees of substitutability and complementarity can vary significantly across courses and disciplines. For example, audio recording a mathematics lecture may not be very helpful for students who did not attend the lecture, but a good opportunity for those who did attend to clarify points that they missed (low degree of substitutability, moderate degree of complementarity). On the other hand, students may not consider it necessary to attend a history lecture if audio recordings are available (high degree of substitutability); at the same time, students that did attend may welcome the opportunity to listen to the

6 Along these lines, see Correa and Gruver (1987) and Guest (2001).

7 Gomis Porqueras and Rodrigues-Neto (2010) present a game-theoretic model that exposes the different incentives for students and clarifies the dependency between lecture attendance and availability of classroom technology. 
audio recordings to deepen their understanding of the material (high degree of complementarity). These examples also illustrate that degrees of substitutability and complementarity differ across students. In the case of the history lecture, audio recordings offer less complementarity for students who are not auditory learners and who prefer visual or kinaesthetic learning.

The actual attendance decision of a student also depends, of course, on her outside options. Every student faces an array of outside options such as work, leisure, or other lectures arising from time conflicts. A student will not attend lectures if her outside option is sufficiently attractive. Outside options, such as labour-market opportunities and social activities, are not typically under the control of the lecturer or the university. By restricting access to web-based materials, lecturers can increase the cost of missing class. If online materials are an efficient substitute and a poor complement to class, and the only objective of a lecturer is to maximize attendance, then the lecturer should offer as little online material as possible, within university rules.

Policies that govern the availability of online lecture content have significant consequences for the composition of students attending live lectures. Why should we care about class composition? If the content taught in a lecture is influenced by the students that are present, policies on web-based technologies may modify the content of courses. In particular, if the most skilled students are more likely to belong to the group of students with higher degrees of substitutability and better outside options, then these students may not go to classes that provide online access to lecture materials. Given that this group of students typically asks the majority of clarifying questions, their absence could reduce learning for the entire class. If group membership is correlated to other observable characteristics, such as gender, age, nationality, religion, or social status, then providing access to web-based materials will affect the presence of these distinct groups differently.

The empirical literature lends support to the theory outlined here. Students' attendance decisions are highly heterogeneous and they affect class composition. The literature has identified various underlying determinants for absenteeism. For instance, Romer (1993) finds that absenteeism is lower for courses with a significant mathematical component, for core courses, and when the perceived quality of instruction is high. Cohn and Johnson (2006) find that factors that influence a student's decision to attend class include the student's race (nonwhites are more likely to not attend class), Grade Point Average (higher GPA implies better attendance records), Scholastic Aptitude Test to enter university (higher SAT implies lower attendance), college experience (freshmen appear to attend more classes than juniors and seniors), and residence (state residents have better attendance records). These factors have important implications for the composition of lectures. Other determinants are students' social activities. 
For instance, Longhurst (1999) finds that 46 per cent of sampled students admitted missing classes for social, recreational, and leisure activities. Similarly, Marburger (2001) finds that absenteeism is significantly higher on Fridays.

\section{Attendance and Learning Outcomes}

The education literature has identified several benefits of attending live lectures. Student attendance is not only a good predictor of academic performance. ${ }^{8}$ Attendance is also a key component in the education experience as students learn to manage their differences, work in teams, share, and observe the experiences of other students. By observing the arguments of others, students develop and polish their critical thinking skills and study techniques. They are also motivated to study more, to become better and more participative professionals, and better citizens. Moreover, by sharing experiences, university students also establish friendships that last a lifetime and help them to construct valuable professional and social networks. Later in life, they may use these networks to create non-government organisations and cultural groups, to pursue spiritual and political activities, to enhance their culture, and enrich their lives. ${ }^{9}$

The study of the consequences of introducing a new technology into the classroom and how it affects the incentives of students and lectures is comparatively new. There is, however, a substantial amount of research that explores how attendance affects student outcomes. Within the economic literature, Romer (1993) finds that the difference in performance between a student who attends regularly and one who attends sporadically is about a full letter grade. In the same spirit, Durden and Ellis (1995) find that absenteeism is strongly associated with poor academic performance. Similar results are found within the education literature. For instance, Rodgers (2001) and Rodgers and Rodgers (2003) find that attendance has a small, but statistically significant, effect on academic performance. In contrast, Bratti and Staffolani (2002) find evidence that once self-study time is controlled, the positive and significant effect of lecture attendance for some courses disappears.

To the extent that the use of classroom technologies may affect attendance, the effect on academic performance needs to be explored. In this spirit, Brotherton and Abowd (2004) focused on the digital audio recording of lectures and could not find any significant difference in exam grades based on availability of audio records. However, they postulate that students might achieve the same level of

8 For more on students' academic performance and attendance, we refer to Romer (1993) and Durden and Ellis (1995).

9 For more on networks and relationships, see Granovetter (1973) and Gersick et al. (2000) and the references therein. 
performance with less work. Similarly, Traphagan (2005) finds that exam scores did not statistically differ when comparing the webcast and no-webcast sections of a course. On the other hand, Brown and Liedholm (2002) find that economics students instructed solely by video-streamed lecture through the internet perform worse in exams than students receiving real-time and live lectures. In contrast, Day and Foley (2006) find that the recorded section's average grades on all assessments are higher than the live sections, in a course on humancomputer interaction at Georgia Tech. Recently, Figlio et al. (2010) presented the first experimental evidence on the effects of live versus internet media instruction. Students in a large introductory microeconomics course at a major US research university were randomly assigned either to face-to-face lectures or to video-streamed lectures through the internet. Other than that, students in both groups had access to the same resources. ${ }^{10}$ The random assignment made it possible for Figlio et al. to compare the means of the test scores between the two groups, without controlling for characteristics. They find modest evidence that students who attended face-to-face lectures have higher average test scores. When stratifying the estimations along lines of ethnicity, gender, and ability (as proxied by university entrance exams), they find particularly strong effects for Hispanic students, male students, and lower-achieving students.

\section{Incentives for Students}

Students might believe that they must benefit from the availability of additional resources. For example, some students at Harvard University strongly support recording lectures as a means to advance flexibility and accessibility. The student publication the Harvard Crimson Staff (2006), reported: 'The real solution to poor attendance at lectures is simple: high quality, interactive, and engaging lectures. We should not deny students the fruits of new technology merely to force them into the classroom when that technology can substantially enhance their educations.' In sharp contrast, the student publication of the University of California at Berkeley, Daily Californian (2006), writes: 'Webcasts are a concession to student apathy. The broadcasts are essentially an admission of defeat by an academic institution, acknowledging that it is okay to skip class.' These polarized views highlight how students evaluate the different trade-offs that emerge when online technologies are offered in the classroom.

Students have changing objectives when attending university. Before they start their university life, students have strong incentives to enter the most prestigious university possible. This is because they can use their university

10 Students could access quizzes and past exams through the class website. There was also no difference in access to consultation times. 
affiliation to signal their high quality to the labour market. But once admitted - assuming a high probability of completing a degree — students have an incentive to demand services that can lower the cost of their academic life as a student. The typical demand by student organizations is for all lecturers to provide web-based lecture materials. However, not all of the students' shortrun objectives and incentives are necessarily aligned to the best interests of students and society in the long-run. This is especially true in competitive job-market environments. These short-run and long-run considerations should be taken into account when designing policies that regulate the availability of online lecture content.

\section{How New Technologies Alter the Incentives for Lecturers}

In thinking about the incentives for lecturers, we follow Becker $(1975,1979$, 1982). His classic papers on education develop a theoretical framework for analysing the behaviour of a university professor. Becker assumes that faculty time is a variable input to various academic outputs; that is, the production of research and teaching outputs. He finds that an increase in the pecuniary return of teaching will raise teaching quality, while exogenous changes in teaching and/or research technology may not. Becker's papers emphasize the importance of correctly measuring academic outputs, such as the quality of teaching. Becker (1979) proposes student evaluations and standardized student-learning measures so that financial rewards could be tied to teaching performance. The incentives to increase productivity in teaching are then tightly linked with the quality of the measures used by the administration to capture the lecturer's effort and quality.

Another important aspect that affects the instructor's decision to allocate resources to teach is to have a sense of student heterogeneity. For expositional purposes, let us simplify the student body and just consider two types of students: academic and non-academic. The academic student is likely to already have some prior knowledge, and is highly motivated to gain a deeper understanding of the subject. Typically, these students pursue higher degrees. On the other hand, non-academic students are mainly motivated by the desire to pass their courses and to obtain a certification that will allow them to find a job. The particular mixture in the class will affect the instructor's choices regarding time allocation and teaching method.

Thus, it is crucial to analyse how technology might affect the production of research and teaching outputs when facing a heterogeneous student population. Not only is it important to decide whether to allow access to web-based lecture 
materials, but it is also crucial to determine the type of digital technologies to use, because they induce different incentives for students to attend class. The lecturer cannot control the outside options of students. She can, however, choose, to a certain degree, the types of technology offered in her course. In practice, this is relevant because lecturers and universities have some control over the degree of substitutability and complementarity of different online materials. For instance, a lecturer can record lectures using mp3 formats that allow students to download lectures and listen to them when they want. On the other hand, the lecturer can provide recording materials that cannot be downloaded and have a time window during which students can access those materials. These different options change the relative degree of substitutability and complementarity of web-based materials, and thus the incentives to attend class change.

We have explained above that different choices of web-based technologies will lead to different compositions of students attending lectures. Why should a lecturer care about class composition? Most universities subject their lecturers to regular teaching evaluations. It is commonly expected that lecturers will strive for 'teaching excellence' and, where this is not attained, to engage in activities that improve teaching quality (for example, by enrolling in teaching courses). In most cases, teaching quality is evaluated by the students at the end of the semester via paper-based or online teaching evaluations. Traditional paper-based evaluations require student attendance in a lecture. Therefore, if academic career concerns depend on teaching evaluations, the lecturer has an interest in influencing the composition of students in his class. Web-based materials give the lecturer a tool to do so. ${ }^{11}$

On the other hand, online-based evaluation methods have become more pervasive. These methods allow students to evaluate their lecturers within a certain time window at the end of the teaching term and do not require actual attendance at lectures. An investigation of the optimal blend of teaching technologies to maximize student-evaluation outcomes in this case, or in general, is beyond the scope of this paper. However, it is clear that lecturers face obvious strategic choices that they should exploit to their benefit if they are rational, within university policy constraints.

11 For the Australian experience in teaching evaluations, we refer to Hirschberg (2007) and Davies et al. (2006). 


\section{How New Technologies Alter the Incentives for Administrators}

In these early stages of new online technologies, there has been confusion and disagreement between university administrators and lecturers over the use of new technologies. Some new web-based tools that are extremely efficient for marketing purposes may be less than ideal in the classroom, where the main goal is education. Some famous universities use modern technology as a marketing tool to attract the most intelligent students to their campuses. Once they are enrolled, these universities use blended-learning techniques to advance student education. Some of these tools are well tested throughout history. For instance, Harvard strongly encourages study groups in which students meet and discuss what they have learned in lectures. This approach requires no new technology. It is an old-fashioned, yet very successful, method of study that promotes participation and social interaction among students. ${ }^{12}$

Moreover, providing easy access to education is very important in some universities and courses, but less so in others. When designing policies regarding classroom technology, university administrators should differentiate between courses that are purely web-based and those that require the students' presence, as their student bases are quite different. This is because the nature and content of materials can be significantly different. For instance, institutions that specialize in distance learning deliver education to students who are not physically 'on site' and have to rely on online technologies. On the other hand, more traditional institutions - those requiring face-to-face interactions that offer more curriculum options - are less dependent on online technologies. In particular, traditional institutions offer subjects and courses that require students to be physically present to conduct, among other activities, laboratory experiments, group projects and presentations. These are key components of the educational experience for all students.

The optimal speeds, goals and designs of courses offered in these two types of institutions may be very different. Ideally, the web-based materials that live courses in traditional institutions provide tend to complement the materials covered in live lectures. In contrast, the types of materials used by distancelearning institutions provide online courses that are substitutes to live classes at traditional institutions. Thus, when implementing policies that regulate the availability of online lecture content, it is important to distinguish the nature of the institution at hand, as their student populations and objectives are quite different.

12 For the foundations and benefits of group performance, see the seminal works of Slavin (1980), McGrath (1984) or Johnson and Johnson (1994). 
The objective of universities, as non-profit institutions, is to educate and nurture students, to create knowledge, and to provide service to the community. It is not to maximize the short-run income of students. As a result, institutions of higher learning protect their reputation and the quality of their education. It is crucial for institutions of higher learning to understand the consequences of introducing classroom technology for student learning outcomes.

\section{Concluding Remarks}

A priori, it seems that greater flexibility and more options would be beneficial, or at least neutral, to the learning processes; however, the net effect on students' learning outcomes remains an open question. The availability of technology in the classroom will benefit some students while other students will be affected adversely. Further, the lecturer has some incentive to exploit technologies to his benefit. The net effect on students' learning outcomes is likely to be different in distinct circumstances. A one-size-fits-all mandatory policy on web-based lecture content across campus is unlikely to be effective, and may hurt the reputation of leading academic institutions. It may also have a significant impact on class composition.

Finally, even when students have a utility-maximising response to new technologies, taxpayers are crucial stakeholders in providing the funds to enable universities to buy web-based learning management systems. Thus, university educational policies should ensure that taxpayers' dollars are used wisely and efficiently, as there are alternative uses for these funds. ${ }^{13}$

\section{References}

Adeyemi, M. and Adeyinka, A. 2002, 'Some Key Issues in African Traditional Education', McGill Journal of Education, 37(2): 233-5.

Akinnaso, N. 1998, 'Schooling, Language, and Knowledge in Literate and Nonliterate Societies', Cultures of Scholarship, University of Michigan Press, 339-86.

Babcock, P. and Marks, M. 2010, 'The Falling Time Cost of College: Evidence from Half a Century of Time Use Data', NBER Working Paper No. 15954.

13 In response to the findings of the Bradley Review, the Australian government is supporting higher education and research with an additional $\$ 5.4$ billion over four years and will commit additional resources over the next 10 years. This includes funding of $\$ 1.5$ billion for teaching and learning. 
Becker, W. 1975, ‘The University Professor as a Utility Maximizer and Producer of Learning, Research and Income', Journal of Human Resources 10: 107-15.

Becker, W. 1979, 'Professional Behavior Given a Stochastic Reward Structure', American Economic Review 69: 1013-24.

Becker, W. 1982, 'The Educational Process and Student Achievement Given Uncertainty in Measurement', American Economic Review 72: 229-36.

Benzing, C. and Christ, P. 1997, 'A Survey of Teaching Methods Among Economics Faculty', Journal of Economic Education 28: 182-8.

Bratti, M. and Staffolani, S. 2002, 'Student Time Allocation and Educational Production Functions', University of Ancona Department of Economics Working Paper No. 170.

Brotherton, J. and Abowd, G. 2004, 'Lessons Learned From eClass: Assessing Automated Capture and Access in the Classroom', ACM Transactions on Computer-Human Interaction 11: 121-55.

Brown, B. W. and Liedholm, C. E. 2002, 'Can Web Courses Replace the Classroom in Principles of Microeconomics', American Economic Review Papers and Proceedings 92(2) (May): 444-8.

Cohn, E. and Johnson, E. 2006, 'Class Attendance and Performance in Principles of Economics', Education Economics 14(2): 211-33.

Correa, H. and Gruver, G. 1987, ‘Teacher-Student Interaction: A Game Theoretic Extension of the Theory of Education', Mathematical Social Sciences 13: 1947.

Daily Californian Editorial 2006, 'Send the Webcast Back to the Stone Age', The Daily Californian, 31 October 2006, http://www.dailycal.org/sharticle. php?id=22059

Davies, M., Hirschberg, J., Johnston, C., Lye, J. and McDonald, I. 2006, 'What Influences Teaching Evaluations? Evidence from a Major Australian University', The Business Review, Cambridge 6(1): 146-52.

Day, J. and Foley, J. 2006, 'Evaluating Web Lectures: A Case Study from Human Computer Interaction', Experience Report - User-Centered Design for Learning Education: 195-200.

Dolton, P., Marcenaro, O. and Navarro, L. 2003, 'The Effective Use of Student Time: A Stochastic Frontier Production Function Case Study', Economics of Education Review 22: 547-60. 
Durden, G. C. and Ellis, L. V. 1995, 'The Effects of Attendance on Student Learning in Principles of Economics', American Economic Review 85(2): 3436.

Figlio, D. N., Rush, M. and Yu, L. 2010, 'Is it Live or is it Internet? Experimental Estimates of the Effects of Online Instruction on Student Learning', NBER Working Paper, No. 16089.

Gersick, C. J., Bartunek, J. M. and Dutton, J. E. 2000, 'Learning from Academia: The Importance of Relationships in Professional Life', The Academy of Management Journal 43(6): 1026-44.

Gomis Porqueras, P. and Rodrigues-Neto, J. 2010, 'Adopting New Technologies in the Classroom', ANU Working Papers in Economics \& Econometrics, Working Paper No. 528.

Gosper, M., Green, D., McNeil, M., Phillips, R., Preston, G. and Woo, K. 2008, 'The Impact of Web-Based Lecture Technologies on Current and Future Practices in Learning and Teaching', Australian Learning and Teaching Council.

Granovetter, M. S. 1973, 'The Strength of Weak Ties', American Journal of Sociology 78(6): 1360-80.

Guest, R. 2001, 'The Instructor's Optimal Mix of Teaching Methods', Education Economics 9: 313-26.

Guest, R. 2005, 'Will Flexible Learning Raise Student Achievement?' Education Economics 13(3): 287-98.

Harvard Crimson Staff 2006, 'Harvard', The Harvard Crimson, 14 February 2006, http://www.thecrimson.com/article.aspx?ref=511262

Hirschberg, J. 2007, 'Systematic Influences on Teaching Evaluations: The Case for Caution', Australian Economic Papers 46: 18-38.

Johnson, D. W. and Johnson, R. T. 1994, Learning Together and Alone. Cooperative, Competitive, and Individualistic Learning, Fourth Edition, Allyn and Bacon, Needham Heights, MA.

Longhurst, R. J. 1999, 'Why Aren't They Here? Student Absenteeism in a Further Education College', Journal of Further and Higher Education 23(1): 61-80.

Marburger, D. R. 2001, 'Absenteeism and Undergraduate Exam Performance', Journal of Economic Education 32(2): 99-109. 
Massingham, P. and Herrington, T. 2006, 'Does Attendance Matter? An Examination of Student Attitudes, Participation, Performance and Attendance', Journal of University Teaching and Learning Practice 3(2): 82103.

McGrath, J. E. 1984, Groups: Interaction and Performance, Englewood Cliffs, NJ, Prentice-Hall.

McInnis, C. and Hartley, R. 2002, 'Managing Study and Work: The Impact of Full-Time Study and Paid Work on the Undergraduate Experience in Australian Universities', Department of Education, Science and Training, Canberra.

Peltzman, S. 1975, 'The Effects of Automobile Safety Regulation', Journal of Political Economy 83(4): 677-726.

Rodgers, J. R. 2001, 'A Panel-Data Study of the Effect of Student Attendance on University Performance', Australian Journal of Education 45(3): 284-95.

Rodgers, J. L. and Rodgers, J. R. 2003, AAn Investigation into the Academic Effectiveness of Class Attendance in an Intermediary Microeconomic Theory Class', Education Research and Perspectives 30(1): 27-41.

Romer, D. 1993, 'Do Students Go to Class? Should They?' Journal of Economic Perspectives 7(2): 167-74.

Schmidt, R. 1983, 'Who Maximizes What? A Study in Student Time Allocation', American Economic Review 73(2): 23-8.

Slavin, R. E. 1980, 'Cooperative Learning', Review of Educational Research 50(2): 315-42.

Traphagan, T. 2005, 'Class Lecture Webcasting, Fall 2004 and Spring 2005: A Case Study', University of Texas-Austin working paper. 